\title{
An Introduction Assessment of Household Waste Management Strategy Problems and its Impact in Capital City of Dili: A Preliminary Literature Review
}

\author{
Augusto Almeida da Silva ${ }^{1,4^{*}}$, Maryono Maryono ${ }^{2,4}$ and Ferry Hermawan ${ }^{3,4}$ \\ ${ }^{1}$ Master of Environmental Studies, School of Postgraduate Studies, Diponegoro University \\ ${ }^{2}$ Departement Urban and Regional Planning, Faculty of Engineering, Diponegoro \\ University \\ ${ }^{3}$ Departement Civil Engineering, Faculty of Engineering, Diponegoro University \\ ${ }^{4}$ Center for Green Infrastructure Resilience Development, School of Postgraduate Studies \\ Diponegoro University
}

\begin{abstract}
The waste management strategy is expected to minimize the negative impact on the environment. In the capital city of Dili, the waste management strategy can be categorized as very concerned. Based on the data from the Ministry of State Administration shows that in 2020, people in the capital of Dili produce waste 250 tons per day. The reality of solid waste in the capital city of Dili shows a severe problem in the waste management process and strategy. This study aims to examine problems in waste management strategies and their impact in the capital city of Dili. Through a literature review approach, a scientific study will be carried out on several scientific articles related to the waste management system and the reality of solid waste in capital city of Dili. The results show that people in the capital of Dili, still use the classical system in managing solid waste. Weak government system and local regulations regarding to solid waste management, and the lack of the waste management industry based on R3 (reduce, reuse, recycle) are the main factors for the community still using the classical system. This reality harms the environment and people in the capital of Dili.
\end{abstract}

\section{Introduction}

The reality of the universe, the environment in particular lately has caught the attention of all parties. How come? The environment that should be a place of interaction for humans and other excellent and comfortable creatures has become alienated from the principles of a healthy life. Efforts to fulfill basic needs sometimes make people forget themselves and fall into selfish attitudes, which result in a prolonged crisis, namely pollution that leads to an

* Corresponding author: gustoalsi92@gmail.com 
environmental problem. The problem was marked by an imbalance and natural destruction marked by climate change, seasonal uncertainty, a flood, etc.

Timor Leste is one of the developing countries globally, which is in the early phase of increasing the percentage of waste. This fact is indicated by the weakness of the waste management system taking place in the lives of the people of Timor Leste, especially in the capital city of Dili. From 2014 to 2021, there were serious problems in the waste management strategy in the capital city of Dili. Based on the Asian Development Bank's statistical data, it is estimated that the volume of waste covered by the TPA (final collected waste) will reach 18,564 cubic meters per day [1]. Meanwhile, data from the Ministry of State Administration (Ministerio Administrasaun Estatal-MAE) describe that people in the capital city of Dili produce 250 tons of waste every day [2]. The reality of a large amount of waste production indicates a problem in the waste management strategy in the community. The increasing human population and urbanization are the determining factors for the increase in waste around the community [3].

The phenomenon of increasing waste production in the capital city of Dili is uncontrollable. The consequence is the emergence of pollution in the environment. The right way to prevent negative impacts on the environment from increasing waste is to prioritize a systematic, comprehensive, and sustainable waste management strategy. The current potential issue of waste management is the overcapacity of landfills and methane emission monitoring [4].

\section{Literature Review}

\subsection{Etymology of Waste}

Waste is a substance or remaining object that humans use in everyday life. Efforts to define waste depend on the statutory system in a country. In general, waste is understood as the remnants of materials used by humans in their lives that are no longer used, which have an impact on the human environment, both positively and negatively [5]. Waste has different levels of biodegradability. Some are easily broken down, and some take a long time to break down. Organic waste is waste that is easily decomposed by a very natural process without human involvement. In contrast, inorganic waste requires human involvement to break down through a long phase and time [6].

Waste is not only limited to useless products from human activities. With the skills and proper handling strategies, it can transform waste into a new product that is useful for human needs. So, waste is not only understood as the useless remains of human creations. Efforts to make waste into a functional new product require developing a good, correct, and sustainable management strategy. A qualified management strategy for waste products can certainly minimize the growth and increase of waste in an environment or the community. In addition, it can increase the productivity of the creative economy and create aesthetics for the environment.

\subsection{Waste Management Strategy}

The waste management strategy is the right step to deal with the uncontrolled increase in waste. Waste handling steps are promoted through sorting, collecting, transporting, and processing [7]. In addition to dealing with the level of garbage added, it creates a high sense of human solidarity with the environment and increases economic income through a waste management strategy. 
The implementation of the waste management strategy is always at different levels and contexts and sources of productivity or waste generation. Fundamentally, the objectives of handling all types of waste produced from various sources are always identical, but there are also essential differences. The difference between waste management strategies from different sources is the way how to handle them. For example, household waste and industrial waste have other ways of handling. Things that need to be considered in the household waste management system include avoiding hazards to public health and the environment, not causing risks to air, water, soil, flora, and fauna, and not disturbing others with bad odors [8]. There is a schematic of the household waste management strategy which can be seen in Fig 1.

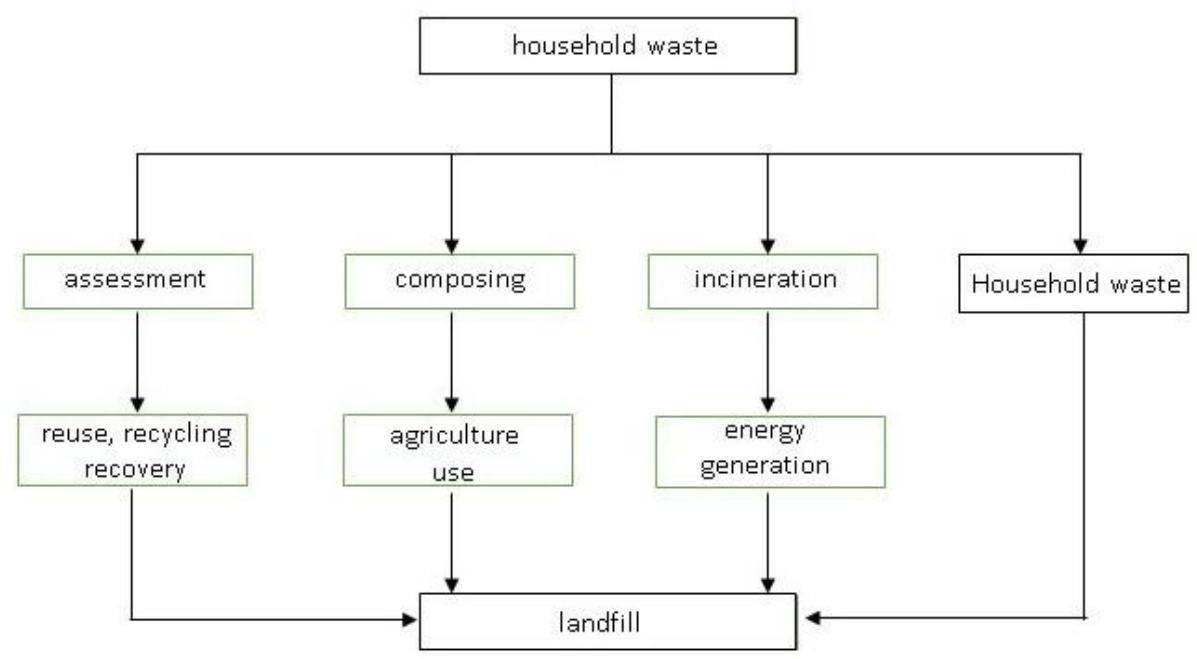

Fig 1. household waste management strategies.

Based on Fig 1 above, it needs to be underlined that the household waste management system is divided into two parts, namely organic waste and inorganic waste. This organic waste management can be done by making compost with benefits in the agricultural sector or burning it to create energy generators. Whereas inorganic waste can be managed by good sorting of each litter, then the $3 \mathrm{R}$ system is applied to increase economic income and create environmental aesthetics.

\section{Methodology}

This research design is a literature review oriented to understand the issues regarding waste management strategies and their impact on life and the surrounding environment. Through data collection methods or sources related to waste management strategies and their consequences, try to make a systematic, argumentative, and accurate literature review and can be scientifically justified.

This literature review uses a descriptive narrative method by classifying the sources of extraction results to answer the objectives of the literature review study. The analysis of descriptive data types builds an approach based on predetermined research sources, then conducts studies and studies of these sources [9]. 


\section{Result and Discussion}

Timor Leste is one of the developing countries which just declared its independence on May 20,2002 . As a new country in the process of growth and development, there are various problems [10]. One of the severe problems faced by Timor Leste, especially in the capital city of Dili, is waste. Waste is a big problem and is often found in all corners of the city of Dili. Government through Decree-Law No. 5/2011 defines waste as any solid, liquid, gas, or radioactive matter that causes transformations when unloaded in the environment and result from individuals or private and public institutions activities.

Economic activities in several strategic market places, such as Becora market, Taibesi market, Manleu market, Comoro market, and Tasi-Tolu market, have become a massive source of waste production. In addition, community activities in each village also contribute to the growth rate of waste in the capital city of Dili. For example, household waste. The absence of an adequate and sustainable waste management strategy makes the solid waste phenomenon challenging to overcome. This reality is strongly supported by statistical data from the ministry of state administration which explains that people in the capital city of Dili each day produce 250 tons of waste. The classification consists of $33 \%$ tree leaf waste, $18 \%$ plastic waste, $18 \%$ paper waste, and the rest are food scraps, including beverage cans [11].

In the absence of a reliable management strategy in managing waste, it can be concluded that the people in the capital city of Dili still use the classic handling methods in managing waste. A system includes waste collection, transportation, and throwing it away in the place provided without good sorting [12]. This classic waste management system also influences the mindset of the people of the capital city of Dili. The people make themselves the ones to be served by the government. The cleaners of the city of Dili transport the waste that is dumped at every TPS (temporary collected waste).

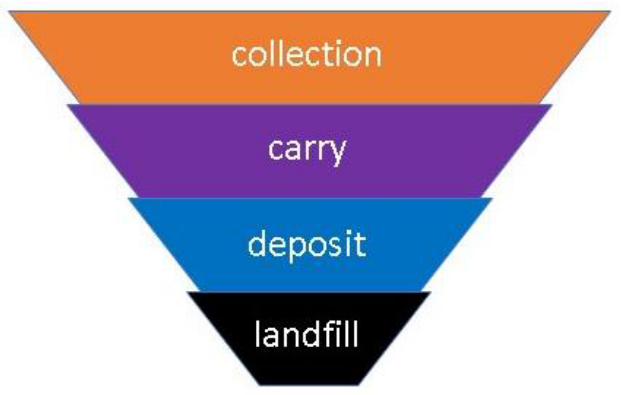

Fig 2. waste management strategy in East Timor.

In a scientific study on the waste management system in the capital city of Dili, it was found that only $45.9 \%$ of households/communities were able to sort out waste; the remaining excess did not separate the waste produced. From the respondent's data statistics, the sorted waste includes cans, organic, glass, plastic, and paper. The classification of waste can only have the potential to be sold (72\%) [13]. This situation indicates that other types of waste cannot be used properly. They were finally disposed of in a temporary landfill until transported by truck to the final collection area. Interestingly, when synchronized with data from the ministry of state administration which records 250 tons of waste every day, there are $31 \%$ types of food waste (including cans), illustrating that $69 \%$ of waste is not properly processed with an ideal waste management system. The reality of the waste management strategy certainly harms other people's lives and the surrounding environment. The negative impacts of the classical management system in the capital Dili, such as (1). increasing waste, (2). threatens public health, and (3). Environmental pollution. 
Based on the fact of the classical waste management system, (see Figure 2), and analysis of Zulmira Ximenes da Costa et al. [14] and statistical data from the ministry of state administration [15], in my opinion, people in the capital of Dili need to increase their responsibility and raise awareness about the impact of the classic waste management system. In addition to the personal-individual factors of each community in managing waste, in my opinion, several priority steps can support the individual spirit of each community in managing waste, including (1) socialization from related parties, in this case, the ministry of environment and ministry of administration state, (2) seriousness in embodying Decree-Law No. 5/2011 into a work program with regulations, (3) creating a waste management industry with a $3 \mathrm{R}$ system.

\section{Conclusion}

Waste will not just disappear from human life. When humans are still on the move, at the same time, waste productivity increases. Waste will be a disaster for humans and the environment if there is no ideal management strategy. On the other hand, the perfect waste management strategy can create new products, increase economic income, and minimize pollution to the environment. The government needs to work together with NGO groups to pursue the ideal steps to prevent waste from rising in the capital city of Dili. Based on this work, activities are pursued outreach to the community regarding the perfect waste management strategy, introducing the 5R system (Rethink-Elimination, Reduce, Reuse, Recycle, and Recovery). Rethink-Elimination and Reduce are an initial steps to prevent and minimize the increase of waste. Reuse, Recycle, and Recovery are the steps to revive and increase economic income.

\section{References}

1. A. Woodruff, Asian Development Bank, 2 (2014)

2. Z. Vieira, Neon Metin Report http://neonmetin.info/buletin/2021/02/16/komunidadedili-kada-loron-produz-lixu-250-ton-55-ba-tibar-15-ba-valeta-no-tasi/ accessed on 25 April (2021)

3. A. Demirbas, Energy Conversion and Management an International Journal 52, 1281 (2011)

4. N.A. Chusna, M. Maryono, Preliminary Evaluation of Method to Monitor Landfills Resilience against Methane Emission, E3S Web of Conferences, Vol 312018 , https://doi.org/10.1051/e3sconf/20183105006

5. G. Lamb, S.R. Pongson, D. Schliebs, Department of Sustainable, Environment, Water, Population and Communities, 2, 17-19 (2012)

6. R. Chandrappa, D.B. Das, Solid Waste Management, (2012)

7. A. Demirbas, Energy Conversion and Management an International Journal 52, 1281 (2011)

8. N. Chuks Nwachukwu, F. Anayo Orji, O. Chinyere Ugbogu, Health Care Waste Management - Public Health Benefits, and the Need for Effective Environmental Regulation Surveillance in Federal Republic of Nigeria, (2013)

9. S.P. Hadi, Metodologi Penelitian Lingkungan Bidang Sosial (2017)

10. World Bank, Sustainable Development Department, East Asia and Pacific Region (2009) 
11. Z. Vieira, Neon Metin Report http://neonmetin.info/buletin/2021/02/16/komunidadedili-kada-loron-produz-lixu-250-ton-55-ba-tibar-15-ba-valeta-no-tasi/accessed on 25 April (2021)

12. Z.X. da Costa, B.B.H.C. de Jesus, IJERT (International Journal of Engineering Research \& Technology), 7 (2018).

13. Z.X. da Costa, B.B.H.C. de Jesus, IJERT (International Journal of Engineering Research \& Technology), 7 (2018).

14. Z.X. da Costa, B.B.H.C. de Jesus, IJERT (International Journal of Engineering Research \& Technology), 7 (2018).

15. Z. Vieira, Neon Metin Report http://neonmetin.info/buletin/2021/02/16/komunidadedili-kada-loron-produz-lixu-250-ton-55-ba-tibar-15-ba-valeta-no-tasi/ accessed on 25 April (2021) 